PESHAWAR JOURNAL OF PSYCHOLOGY AND BEHAVIORAL SCIENCES, 2019, VOL. 5, NO. 1, 39-52

\title{
Perceived Parenting Styles among Drug Addict and Non-Addict Medical Students
}

\author{
Salma Rehman ${ }^{1}$ and Madiha Asghar ${ }^{2}$ \\ Islamia College Peshawar
}

Current study was aimed at studying the difference between the perceived parenting styles of drug addict and non-addict medical students. Total sample of the study was two hundred $(\mathrm{N}=200)$ medical students that comprised of one hundred addict $(\mathrm{n}=100)$ and one hundred $(\mathrm{n}=100)$ non-addict medical students with age range of 18 to 29 years. Data was collected from different medical colleges in Khyber Pakhtunkhwa through convenient and snow ball techniques. Data was collected through adolescent's alcohol and drug usage scale (Moberg, 1991) and parenting styles questionnaire (Buri, 1991). The results of the study indicated that authoritative parenting style was significantly reported by non-addict medical students, whereas addict medical students reported higher scores on authoritarian parenting styles. It can be therefore concluded from the findings of the study that parenting styles play a significant role in the mental wellbeing and promotion of healthy habits among youth. The study supports the idea that controlling parenting style may contribute to promote mental health problems among youth such as drug addicting.

Keywords: drug addiction, authoritarian parenting styles, authoritative parenting styles, permissive parenting styles and medical students

Substance use is a major public health issue affecting the health and wellbeing of individuals globally substance use is a major public health

\footnotetext{
${ }^{1}$ Lecturer, Department of Psychology, Islamia College Peshawar contact salma@icp.edu.pk

${ }^{2}$ Assistant Professor and Head, Department of Psychology, Islamia College Peshawar
}

ISSN 2415-6779 EISSN 2518-4474

https://doi.org/10.32879/picp.2019.5.1.39

www.pjpbsicp.com 
issue affecting the health and well-being of millions of Pakistanis (Government of Pakistan's Ministry of and Interior and Narcotics Control, Pakistan Bureau of Statistics, and the United Nations Office on Drugs and Crime, 2013). Medical students are not exempted from the consequences of substance use which may include academic, work and social impairment (Centers for Disease Control and Prevention, 2016). Factors including personal, family and social are effective in the continuance after treating the addiction dependence (Dabbaghi, 2007). Gossop M., \& Grant, M. (1990) reported that parenting styles are generally predictive of drug addiction. However some research suggest that there is need of investigation of the causative factors related to drug addiction among highly intelligent students of medical colleges, who are not only highly intelligent but they are well aware of the mechanism and the consequences of drug addiction (Coombs \& Landsverk 1988). It is therefore aimed at studying the relationship between parenting style and leading to drug addiction among medical students, the health care providers.

Addiction is the compulsive seeking and usage of drugs that mentally and physically made person dependent on drug and overshadow all personal and social behaviors and invaded human society as the most important of social susceptibility (keltikangas, Kivimaki, Keskivaara, 2003).

Diana Baumrind (1991) described the authoritative, authoritarian and permissive style of parenting. These styles are based on two opposite pole of parenting behavior; one is warmth and the other is control. Parenting control are actions parents used in the behavior regulation and modification of their children's. It range from setting vary rigid demands as in authoritarian style of parenting to very few demands on their childrenlike in permissive style of parenting. While parenting warmth refers to the nurturance and unconditional positive regard and acceptance that parents gives to their children's. It also can range from very high in the form of permissive style and moderate in the form of authoritative.

A national base line survey (2004) on alcohol and substance use highlights that alcohol and substance abuse is on increase among youth and that one in every eight people who take substance and alcohol on transient and recreational basis are addicted to it.

Drug abuse is prevailing day by day in Pakistani's youth, which is account almost $28 \%$ of the whole population of Pakistan (Niaz, Siddiqui, Hassan, Ahmed, \& Akhtar, 2005). According to Bureau of Statistics of Pakistan (2013) sixty four lac people in Pakistan are engaged in drug abuse annually, in which cannabis is more common. Newly emerged trend of drug abuse in Pakistan is considered is "Sheesha" (Ice), which is more

PESHAWAR JOURNAL OF PSYCHOLOGY AND BEHAVIORAL SCIENCES, 2019, VOL. 5, NO. 1, 39-52 
frequently consumed by upper class persons both male and female (Ministry of Narcotics Control, Islamabad, Year Book,2012).

Research findings revealed that rebelliousness is found in children of authoritarian parenting style which make them susceptible for drug addiction (Hayes, Smart, Toumbourou \& Sanson, 2004). Authoritarian parenting style was found to be one of the predisposing factor behind drug addiction while permissive style has no effect on adolescents drug use and the authoritative style of paternal and maternal parenting has a negative relationship with drug addiction (Zeinali, Vahdat \& Gharadinge, 2010). In addition to negative effects on the individual mental and physical health substance abuse effect individual relation with the families, patients and community at large. They also decrease their empathy level and affect the image of individual as a role model for healthy life style and as a teacher (Bohigian \& Croughan, 1996; Gray et al., 1998; Bennett \& O'Donovan, 2001).

One of the important factor among others in the rate of predisposition to drug use is parenting style. Maccoby, E, Martin J. (1983) revised the classic model of Baumrind's. They classified the parental style based on two characteristic of responding rate and expectation rate. Expectation rate indicate that parents anticipate experienced behavior from their children and responding rate points out that the parents shows acceptance and affective warmth and engage themselves in children actions and behavior. Based on this classification three style of authoritative, authoritarian and permissive wad introduced. Pellerin, L. A. (2005) examined that children of authoritative parents have better mental health where as children of authoritarian parents shows lower deficient social skills and more proneness toward behavioral problem and drug use. Children of permissive parents have difficulty in adjustment to an educational issues and high average in drug use and behavioral problems. Wood, et. Al. (2004) found that permissive parenting style permissive parenting significantly predict substance abuse. Another study investigated that authoritarian parenting style the increased in alcohol abuse (Hayes, L. et al. 2004). Zeinali, A., Vahdat, R. and Gharadinge, K. (2010) specified that authoritative parenting style of mother and father has a negative correlation with addiction probability.

Christakis, Fowler and Shakya (2012) investigated the effect of parenting style of friend's parent's influence on adolescent's drug use which is partially mediated through the behavior of the peers. Authoritarian parenting style was mostly used by the parents of drug 
addicted medical students and the behaviors of those students affect their peer behavior that can indirectly contribute to the use of drug among them.

Research has long indicated that parenting style is important (Bornstein, 2003), and that it significantly predicts drug addiction among students (Weiss and Schwarz, 1996). The purpose of the present study was to investigate the relationship between parenting style and drug addiction among medical students. Further the current study aimed that which type of parenting style will significantly predict drug addiction among medical students.

\section{Objectives}

1. To investigate the perceived parenting styles of addict and nonaddict medical students of Khyber Pakhtunkhwa

2. To study the effect of perceived parenting styles on the basis of gender among addict and non-addict medical students of Khyber Pakhtunkhwa

\section{Hypotheses}

1. Medical students addicted to drugs will score high on scale for authoritarian parenting style as compared to non-addict medical students.

2. Medical students addicted to drugs will score high on scale for permissive parenting style as compared to non-addict medical students.

3. Medical students addicted to drugs will score lower on scale for authoritative parenting style as compared to non-addict medical students.

\section{Sample}

\section{Method}

Sample of the study was composed of two hundred $(\mathrm{N}=200)$ medical students, further division of the sample includes one addict $(\mathrm{n}=100)$ and one non-addict $(\mathrm{n}=100)$ medical students. Among one hundred addicts medical students eighty seven $(n=87)$ were males and thirteen $(n=13)$ were females Age range for the study was kept between 18-29 years with mean age of 22.65 years. Sampling techniques were used

PESHAWAR JOURNAL OF PSYCHOLOGY AND BEHAVIORAL SCIENCES, 2019, VOL. 5, NO. 1, 39-52 
were snow ball and convenient sampling methods, due to social stigma of drug addiction other sampling technique was no possible.

\section{Tools}

Tools used in the study to measure both independent and dependent variables were:

\section{Demographic data sheet}

Information regarding age, gender, socio economic status, parent's income, parent's profession etc. was taken on demographic sheet.

\section{Adolescent alcohol and drug involvement scale (AADIS)}

D.Paul Moberg (1991) established adolescents' alcohol and drug involvement scale for the purpose to identify drug addicts and non-addicts. This scale is designed as Five point Likert with 14 items, cut-off score for drug addiction is 37 or above than 37 , reliability of the scale is .85 .

\section{Parental authority questionnaire (Parenting to father and mother)}

John.R.Buri(1991) developed parental authority questionnaire and it was translated to Urdu by Barbed in 1997. This scale is used to measures parenting styles of children. The scale consists of total of 60 items. The scale has two parts, parenting to mother and parenting to father each consists of 30 items. Additionally three subscales of this scale measuring authoritative, authoritarian and permissive parenting styles. The scale consists of five points Likert scale ranging from strongly agree to strongly disagree. Subscales reliability coefficient for mother authoritativeness were .78, for mother authoritarianism it were 65 , for mother permissiveness .55 , for father authoritativeness.71, .66 for father authoritarianism, and for father permissiveness it were .53. Score range on each sub-scale variable of parental authoritative questionnaire is from 1050. High score on a variable shows individual appraisal for that Procedure

\section{Procedure}

Formal process for conducting research is to take permission from the authorized institutions and organization, so same as done for this research study. Consent were taken from Peshawar, Mardan and Abbottabad medical colleges. Rapport establishment is necessary for full participation of research participants, so rapport was developed with research participants. Research participants were briefed about the 
objectives of the study. After taking consent from research participants self-administer questionnaires were handed over to them. Research participants were guided during filling the questionnaires while facing any trouble regarding research questionnaires.

\section{Results}

Table 1

Psychometric Properties of Scales Used for Addicts and Non-Addicts $(N=200)$

\begin{tabular}{lccccc}
\hline Scale & No. of items & Mean & SD & $a$ & Skew \\
\hline ADDIS & 16 & 32.74 & 19.87 & .95 & .33 \\
PAQ-M & 30 & 97.13 & 17.79 & .84 & -.04 \\
PAQ-F & 30 & 97.15 & 19.55 & .87 & -.14 \\
\hline $\begin{array}{l}\text { Note: ADDIS: Adolescent Alcohol and Drug Involvement Scale,PAQ-M: Parental } \\
\text { Authoritative Questionnaire (Parenting to Mother), PAQ-F: Parental Authoritative } \\
\text { Questionnaire (Parenting to Father). }\end{array}$
\end{tabular}

Table 2

Logistic Regression Analysis Predicting Parenting Styles for Drug Addiction among Addict and Non-Addict Medical Students (N=200)

\begin{tabular}{|c|c|c|c|c|}
\hline \multirow[b]{2}{*}{ Variables } & \multirow[b]{2}{*}{$\mathrm{b}(\mathrm{SE})$} & \multicolumn{3}{|c|}{ 95\% CI for Odds Ratio } \\
\hline & & Lower & Odds Ratio & Upper \\
\hline Constant & $-.61(.87)$ & & .55 & \\
\hline PM & $.06(.03)^{*}$ & 1.07 & 1.07 & 1.13 \\
\hline AEM & $-.07(.03)^{*}$ & .88 & .93 & .98 \\
\hline ANM & $.05(.03)$ & .99 & 1.05 & 1.12 \\
\hline $\mathrm{PF}$ & $.06(.03) *$ & .88 & .94 & .99 \\
\hline $\mathrm{AEF}$ & $-.04(.02)$ & .91 & .96 & 1.02 \\
\hline ANF & $.02(.08)^{* *}$ & 1.02 & 1.08 & 1.14 \\
\hline
\end{tabular}

PESHAWAR JOURNAL OF PSYCHOLOGY AND BEHAVIORAL SCIENCES, 2019, VOL. 5, NO. 1, 39-52 
Table 2 shows Logistic regression analysis of parenting style of drug addiction among medical students. Four of the six predictors shows statistically significantly relationship between constant and predictors while two of the predictors does not contribute significantly to the prediction (chi square 10.97, $\mathrm{p}<.05, \mathrm{p}<.01, \mathrm{df}=6$ ). Overall prediction success is $66 \%$. The Walden criterion demonstrate that Permissive mother, authoritative mother, permissive father and authoritarian father makes a statistically significant contribution to the prediction $(p<.01) . \operatorname{Exp}(B)$ value of permissive mother and authoritarian father indicates as these predictor increase the odds of the outcome occurring increase while the occurrence of outcome decrease as the authoritative style of mother parenting increases.

Table 3

Logistic Regression Analysis Predicting Parenting Styles for drug Addiction among Drug Addict $(n=87)$ and Non-Addict $(n=50)$ Medical Students $(N=137)$.

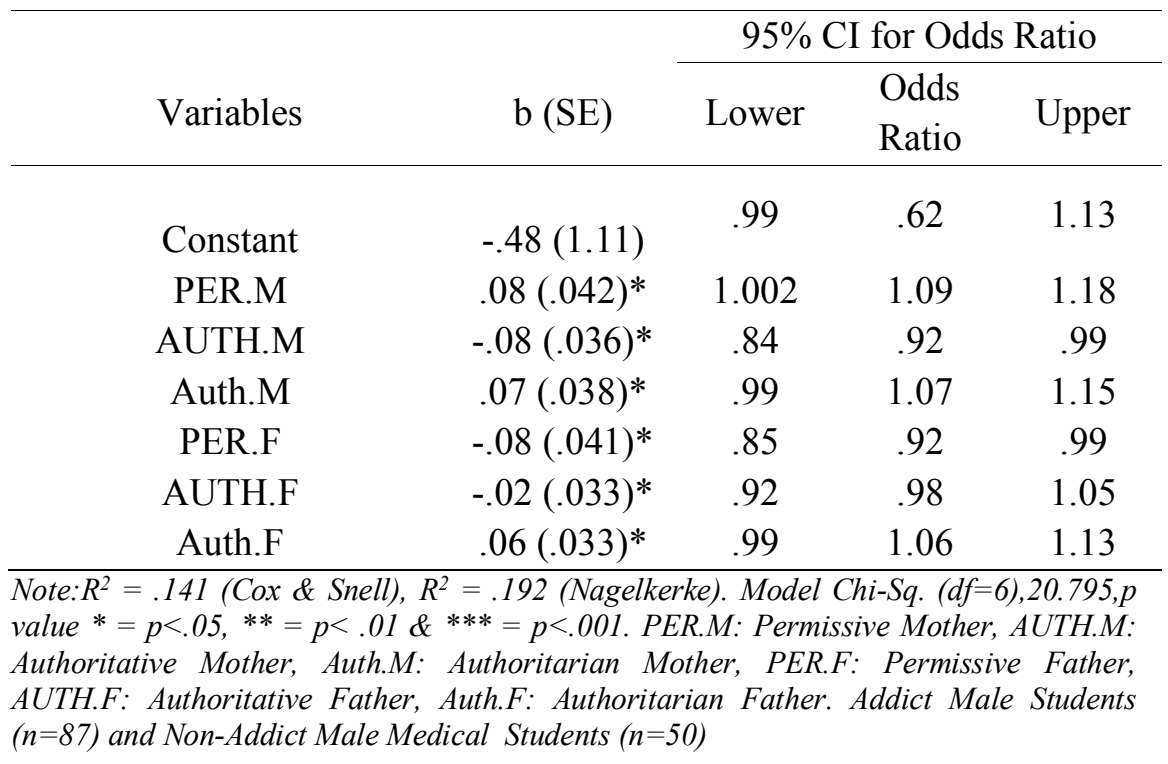

Table 3 shows Logistic regression analysis of parenting style of drug addiction among medical students. Four of the six predictors shows statistically significantly relationship between constant and predictors and contribute significantly to the prediction (chi square $.141, \mathrm{p}<.02, \mathrm{df}=6$ ). Overall prediction success is $66 \%$. The Walden criterion demonstrate that

PESHAWAR JOURNAL OF PSYCHOLOGY AND BEHAVIORAL SCIENCES, 2019, VOL. 5, NO. 1, 39-52 
Permissive mother, authoritative mother, permissive father and authoritarian father makes a statistically significant contribution to the prediction $(\mathrm{p}<.01)$. Exp (B) value of permissive mother and authoritarian father indicates as these predictor increase the odds of the outcome occurring increase while the occurrence of outcome decrease as the authoritative style of mother parenting increases.

Table 4

Response Difference of Female Drug addicts $(n=13)$ and non-addicts $(n=50)$ on Parenting Style Questionnaire. $(n=63)$.

\begin{tabular}{llccccc}
\hline & Group & Mean & SD & Median & Z-Score & p-value \\
\hline Per M & Addict & 32.08 & 8.154 & 28 & -.02 & .98 \\
& Non-Addict & 31.98 & & & & \\
\hline Auth M & Addict & 23.73 & 8.37 & 34 & -1.83 & 0.68 \\
& Non-Addict & 34.15 & & & & \\
\hline Authn M & Addict & 40.96 & 8.03 & 33 & -1.98 & .04 \\
& Non-Addict & 29.67 & & & & \\
\hline Per F & Addict & 33.65 & 7.89 & 27 & -.37 & .71 \\
& Non-Addict & 31.57 & & & & \\
\hline Auth F & Addict & 22.83 & 9.02 & 35 & -1.86 & .074 \\
& Non-Addict & 33.58 & & & & \\
\hline Authn F & Addict & 41.38 & 8.46 & 32 & -2.07 & .03 \\
& Non-Addict & 29.56 & & & & \\
\hline Note: ${ }^{*} p<.05, * * p<.01,{ }^{* * *} p<.001$. Permissive Mother, AUTH.M: Authoritative Mother, \\
Auth.M: Authoritarian Mother, PER.F: Permissive Father, AUTH.F: Authoritative Father, \\
Auth.F: Authoritarian Father.
\end{tabular}

The median of permissive mother parenting style was 28. MannWhitney's U test is used to evaluate the difference in the responses of drug addicts and non-addicts on permissive mother parenting Questionnaire. The result no significant effect of Group (The mean ranks of addicts and non-addicts were 32.08 and 31.98 , respectively; $U=324.0, Z=-0.017, p$ $<0.986)$.

The median of authoritative mother parenting style was 34. MannWhitney's U test is used to evaluate the difference in the responses of drug addicts and non-addicts on authoritative mother parenting Questionnaire. The result shows no significant effect of Group (The mean ranks of addicts and non-addicts were 23.73 and 34.15 , respectively; $\mathrm{U}=217.50, \mathrm{Z}=$ $1.828, \mathrm{p}<0.68)$. 
The median of authoritarian mother parenting style was 33. MannWhitney's U test is used to evaluate the difference in the responses of drug addicts and non-addicts on authoritarian mother parenting Questionnaire. The result shows a significant effect of Group (The mean ranks of addicts and non-addicts were 40.96 and 29.67, respectively; $U=208.50, Z=-$ $1.981, \mathrm{p}<0.048)$.

The median of permissive father parenting style was 27. MannWhitney's $U$ test to evaluate the difference in the responses of drug addicts and non-addicts on permissive father parenting Questionnaire. The result shows no significant effect of Group (The mean ranks of addicts and nonaddicts were 33.65 and 31.57 , respectively; $U=303.50, Z=-.366, p<$ $.715)$.

The median of authoritative father parenting style was 35 . MannWhitney's $U$ test to evaluate the difference in the responses of drug addicts and non-addicts on authoritative father parenting Questionnaire. The result shows a significant effect of Group (The mean ranks of addicts and nonaddicts were 23.92 and 34.10 , respectively; $U=220.0, Z=-1.786, p<$ 0.074).

The median of authoritarian father parenting style was 32. MannWhitney's $U$ test to evaluate the difference in the responses of drug addicts and non-addicts on authoritarian father parenting Questionnaire. The result shows a significant effect of Group (The mean ranks of addicts and non-addicts were 41.38 and 29.56, respectively; $U=203.0, Z=-2.075, p$ $<0.038)$.

\section{Discussion}

The present study was aimed to explore the effect of parenting styles of mother and father on addicted and non-addicted students of medical colleges of Khyber Pakhtunkhwa, Pakistan.

It was hypothesized that parenting style of addicted medical students will be overprotective and authoritarian, whereas parenting style of non-addicted medical students will be authoritative. The finding of the current study are in line with the previous researches (Ahmadi et. al., 2014) conducted in Medical Ilam University of Medical Sciences that drug addiction and authoritative parenting style were inversely related whereas a positive relationship was reported between drug addiction and Authoritarian and permissive parenting style. Further it was found in the present that authoritarian and permissive parenting style makes the 
individual vulnerable for drug addiction while children with authoritative parenting style less likely to prone toward drug addiction. Permissive parenting style was slightly related to drug addiction, only when both mother and father share the same parenting style. In medical student permissive style are reported only in few cases as majority of their parenting style are authoritative and authoritarian in nature.

Similar results was found from previous research study (Pellerin, 2005) that children of authoritative parents have better psychological health and less likely to prone toward unhealthy behaviors like drug addiction as compared children's of permissive and authoritarian parents. The present study yielded consistent result that paternal and maternal parenting styles of the drug addicts in majority of cases are Authoritarian while non-addicts share authoritative style. Authoritarian parents have less understanding of their children emotional state and minimal level of sharing with them so the children of authoritarian parent's uses unhealthy coping mechanisms in the form of drug use to regulate their emotions as compared to authoritative parents who always make sure timely availability to their children emotions and needs.

The findings of the current study are in line with the previous studies (Aslani, Drikvandi \& Dehghani, 2015) that there was a negative relationship between passive addiction and authoritative parenting style and a positive relationship were found between authoritarian parenting style and addiction. Previous studies also show positive relationship between permissive parenting style and addiction potential.

The findings of the present study yielded consistent result with the previous research study conducted on university students (Abikoye, Adekoya \& Sholarin, 2014) that parenting style were significantly associated with substance abuse. Students whose parenting style were authoritative are less likely to prone toward drug addiction as authoritative homes reported high level of more positive outcomes such as having a high level of self-awareness and are able to adjust their emotion in a positive and realistic way. This leads to greater well-being and less behavioral problems including drug involvement whereas authoritarian and permissive homes have reported less positive outcomes and more behavioral problems including drug addiction.

Henceforth this exploration thrived in providing proof that parents have crucial roles in life style medical student. It would be a contribution in the field of drug addiction among medical students in Pakistan. 
Limitation

With contribution of the current research to the existing literature few Limitations were observed while conducting the current study. The size of the sample is the main limitation which includes 100 addicts and 100 non addicts limiting its generalization to the study population. The approach to the addicted group is limited by many factors including social acceptance and expectation of the society from the targeted group on the paradigm of healthy activities.

The present study were limited by the convenient sampling technique used to collect data from medical colleges of Khyber Pakhtunkhwa (KPK, Pakistan) which restricts the generalizability of findings over large population of medical students of Pakistan. The sample of the current study include medical students whose study schedules makes them unable to take out time for completing the study questionnaire with deep concentration effect the significance value of the study variables. Related limitation is the completion of the scales of the current study is time consuming which yield abrupt marking on the scales affecting the significance value and relationship between the variables.

Majority of the students are well aware of what the scale actually measuring, make them vigilant to response in a socially acceptable way, a limitation associated with the validity of the scales. Another limitation is that the instruments are administered in group form, the group pressure and limited privacy also effect the scoring of the respondent them unable to take out time for completing the study questionnaire with deep concentration effect the significance value of the study variables. Related limitation is the completion of the scales of the current study is time consuming which yield abrupt marking on the scales affecting the significance value and relationship between the variables.

\section{References}

Abar, B., Carter K. L., \&Winsler, A. (2009).The effects of maternal parenting style and religious commitment on self-regulation, academic achievement, and risk behavior among African-American parochial college students. J Adolesc, 32, 259-173.

Abikoye, E.G., Adekoya, a. j., Sholarin, M. A. (2014). Parenting styles and peer-pressure as predictors of substance abuse among university students. Psychology and Behavioral Sciences, 3(2), 55-59.

PESHAWAR JOURNAL OF PSYCHOLOGY AND BEHAVIORAL SCIENCES, 2019, VOL. 5, NO. 1, 39-52 
Ahmed, A., Alshagga, A. M., Radman, A. S., Rampal, G. KStress and Coping Strategies of Students in a Medical Faculty in Malaysia. (2014). Malays J Med Sci, 18(3), 57-64.

American psychiatric association (2013). Diagnostic and statistical manual of mental Disorder, $5^{\text {th }}$ ed. American Psychiatric Association, Washington, DC: Dollen and Sons Company.

AslaniKh, Derikvandi N, Dehghani Y (2015). Relationship between parenting styles, religiosity, and emotional intelligence with addiction potential in high schools students. Journal of Fundamentals of Mental Health, 17(2), 74-80.

Bennett J, O'Donovan D (2001) Substance misuse by doctors, nurses and other Health care workers. CurrOpin Psychiatry, 14, 195-199.

Bohigian G. M, Croughan JL (1996). Substance abuse and dependence in physicians: The Missouri Physician's Health Program. Southern Med $J, 89,1078-1080$.

Buri, J.R. (1991). Parental Authority Questionnaire, Journal of Personality and Social Assessment, 57, 110-119.

Bornstein, M. H.(2003). Positive Parenting and Positive Development in children. In R. Lerner, F. Jacobs, \& D. Wertlieb, (eds). Handbook of Applied Developmental Science Volume One: Applying Developmental Science for Youth and Families, Historical and Theoretical Foundations. (pp 187-210). Thousand Oaks: Sage.

Center for Behavioral Health Statistics and Quality. Behavioral health trends in the United States: results from the 2014 national survey on drug use and health: (HHS No. SMA 15-4927, NSDUH Series H-50). [cited 2016 May 19]. Available from: http://samhsa.gov.data

Centers for Disease Control and Prevention. Alcohol and your health. [cited 2019 May 14]. Available from: http://www.cdc.gov/alcohol/pdfs/ alcoholyourhealth.pdf.

Coombs RH, Landsverk J. (1988). Parenting styles and substance use during childhood and adolescence. J Marr Fam, 50(2), 473-82.

Christakis, A. N., Fowler, H.J., Shakya, B.H. (2012). Parental Influence on Substance Use in Adolescent Social Networks Arch PediatrAdolesc Med; 166(12):1132-1139.

Dabbaghi P, Asgharnejad AA, Atef MK, Bolhari J. (2007). [Effectiveness of mindfulness-based cognitive therapy group (mindfulness) and moral schema activation in preventing relapse in opioid]. Iranian Journal of Psychiatry and Clinical Psychology, 13(4), 366-75. (Persian) 
Gossop M, Grant M.(1990). Preventing and controlling drug abuse. World Health Organization: Genev: 132-78.

Government of Pakistan's Ministry of and Interior and Narcotics Control, Pakistan Bureau of Statistics, and the United Nations Office on Drugs and Crime (2013). Drug use in Pakistan. Retrieved from https://www.unodc.org/documents/pakistan/Survey_Report_Final_2 013.pdf

Hayes L, Smart D, Toumbourou JW, Sanson A (2004). Parental influences on adolescent alcohol use. Melbourne: Australian Institute of Family Studies, 175-241.

Keltikangas J, L Kivimaki, M Keskivaara P. (2003). Parental practices, self steem and adult temperament: 17 year follow up study of four population based age cohort. $\mathrm{j}$ Personality and Individual Difference. 5, p 431-ß47.

Ministry of Narcotics Control, Islamabad. Year book 2012.20112012.www.narcon.gov.pk/files/documentsPublicationsAndReports/ Report.pdf.

Maccoby E, Martin J (1983). Socialization in the context of the family: Parent-child interaction. New York: Wiley, 1-101.

National Institute on Drug Abuse (2019) retrieved from www.drugabuse.gov/publications/drug-brains-behavior-scienceaddiction/drug-misuse-addiction

Niaz U., Siddiqui S. S., Hassan H., Ahmed S., Akhtar R. A survey of psychological correlates of Drug abuse in young adults aged 16-24 in Karachi: Identifying 'high risk' population to target intervention strategies. Pakistan Journal of Medical Sciences. 2005 ;(3):271-277.

Pellerin L. A. (2005). Applying Baumrind's parenting typology to high schools: Toward a Middle- range theory of authoritarian socialization. Soc Sci Res; 34: 283-303.

Weiss, L.H., \& Schwarz, J.C. (1996). The relationship between parenting types and older adolescents, academic achievement and substance use: 21012114.

Wood, M. E., Read. J. P., Mitchell, R. E., \& Brand N. H. (2004). Do parents still matter? Parent and peer influences on alcohol involvement among recent high school graduates. Psychol Addict Behav; 18: 19-30.

Yunusa, M.A., Obembe, A., Madawaki, A. \& Asogwa, F. (2011). A survey of Psycho stimulants use among a university students in Northwestern Nigeria. Nigerian Journal of Psychiatry, 9, 40-45. 
Zeinali, A., Vahdat, R., \& Gharadinge, K. (2010). Relationship between parenting style talented addiction in children. Journal of family research 2010; 23(6): 335-52. Cited in Aslani, Kh.,, Derikvandi, N., Dehghani, Y. (2015). Relationship between parenting styles, religiosity, and emotional intelligence with addiction potential in high schools students. Journal of Fundamentals of Mental Health 2015; 17(2): 74-80. 